\title{
Plasma-Driven Catalysis Process for Toluene Abatement: Effect of Water Vapor
}

\author{
Haibao Huang, Daiqi Ye, and Dennis Y. C. Leung
}

\begin{abstract}
Plasma-driven catalysis (PDC) was used to remove toluene in air. Water vapor is a critical operating parameter in this process. Its effect on toluene removal efficiency, carbon balance, $\mathrm{CO}_{2}$ selectivity, and outlet $\mathrm{O}_{3}$ concentration was systematically investigated. Results showed that water vapor imposed negative effect on toluene decomposition since it depressed the formation and catalytic decomposition of $\mathrm{O}_{3}$. Water vapor deposited on the catalyst would cover the catalytic active sites, resulting in the deactivation of the catalyst. There was an optimum water vapor content for the highest carbon balance and $\mathrm{CO}_{2}$ selectivity. The present paper sheds some insight into the effect of water vapor and provides a valuable basis for the application of the PDC technology.
\end{abstract}

Index Terms-Ozone, plasma-driven catalysis (PDC), toluene, water vapor content.

\section{INTRODUCTION}

$\mathbf{P}$ LASMA-DRIVEN catalysis (PDC) technology has attracted much attention in the volatile organic compounds (VOCs) control over the past decades [1]-[4]. It is a promising technology characterized by high energy efficiency and mineralization rate and little by-products formation [5], [6].

Water vapor is a critical operating parameter in the PDC process. Its effect is indeed of great interest since practical applications deal with ambient air that usually contains water [7]-[9]. Water vapor not only affects the concentration of energetic electrons but also gets deeply involved in the formation of oxidants. The effect of water vapor has been intensively studied in the nonthermal plasma (NTP) process and differentiated into enhancement [10], [11], suppression [8], [12], and a dual role [7], [13]. However, few studies have been conducted in the PDC process. The PDC process, quite different from the NTP process, has characteristics of both NTP and the catalysis.

Manuscript received July 11, 2010; revised September 1, 2010 and October 4, 2010; accepted October 4, 2010. Date of publication November 9, 2010; date of current version January 7, 2011. This work was financially supported by the National Key High Technology Research and Development Program of China (Grant 2006AA06A310), Ph.D. Programs Foundation of Ministry of Education of China (Grant 20070561042), and the Committee on Research and Conference Grants of the University of Hong Kong (Grant 200907176159)

$\mathrm{H}$. Huang is with the College of Environmental Science and Engineering, South China University of Technology, Guangzhou 510640, China and and also with the Department of Mechanical Engineering, The University of Hong Kong, Pok Fu Lam, Hong Kong (e-mail: harbor@hku.hk).

D. Ye is with the College of Environmental Science and Engineering, South China University of Technology, Guangzhou 510640, China (e-mail: cedqye@ scut.edu.cn).

D. Y. C. Leung is with the Department of Mechanical Engineering, The University of Hong Kong, Pok Fu Lam, Hong Kong (e-mail: ycleung @ hku.hk).

Color versions of one or more of the figures in this paper are available online at http://ieeexplore.iee.org.

Digital Object Identifier 10.1109/TPS.2010.2086498
Therefore, it is of significance to investigate the effect of water vapor for better understanding and application of PDC technology.

The present paper attempted to clarify the role of water vapor in the PDC process. Two catalysts (i.e., $\mathrm{TiO}_{2}$ and $\mathrm{MnOx}$ ) were used. Toluene was selected as the target VOC pollutant. The effect of water vapor content on toluene removal efficiency (TRE), carbon balance, $\mathrm{CO}_{2}$ selectivity, and outlet $\mathrm{O}_{3}$ concentration were investigated in a more systematic and fundamental manner. The present paper sheds some insight into the effect of water vapor in the PDC process and provides a valuable basis for its application.

\section{EXPERIMENTAL}

\section{A. Experimental Setup}

The experimental setup is illustrated in Fig. 1. Water vapor content in air stream was adjusted by the air flux passing through bubbler for water vapor production. A wire-plate dielectric barrier discharge reactor was used. Its simplified structure is shown in Fig. 1. The epoxy resin board, with the length of $240 \mathrm{~mm}$, width of $50 \mathrm{~mm}$, and thickness of $0.8 \mathrm{~mm}$, was used as dielectric barrier (dielectric constant $\varepsilon=3.6$ ). Copper wire with $0.8 \mathrm{~mm}$ in diameter acted as the high voltage electrode (H.V.). The wire-to-wire distance was $10 \mathrm{~mm}$. A piece of copper mesh $(150 \mathrm{~mm} \times 25 \mathrm{~mm} \times 2 \mathrm{~mm})$ was stuck on the epoxy resin board and acted as the grounded electrode. The gap spacing between the two discharge electrodes was $10 \mathrm{~mm}$. The catalyst mesh was placed on the copper mesh. This kind of reactor owns the advantage of low pressure drop and capability of industrial application.

The experiment was carried out at room temperature $\left(25{ }^{\circ} \mathrm{C}\right)$ and atmospheric pressure. The energy density deposited on the reactor is $651 \mathrm{~J} / \mathrm{L}$ with the power frequency of $50 \mathrm{~Hz}$. Gas samples from the outlet were analyzed online by a gas chromatograph (GC, Kechuang Chromatograph, GC-900A) equipped with two FID detectors. One was for organic compounds detection with a $50-\mathrm{m} \mathrm{SE}-30$ capillary column $\left(80^{\circ} \mathrm{C}\right)$, and the other detector, equipped with a methanizer and a 2-m carbon molecular sieve stainless steel column $\left(65^{\circ} \mathrm{C}\right)$, was for carbon monoxide and carbon dioxide analysis. $\mathrm{O}_{3}$ concentration was measured by an ozone analyzer (Lida Instrument, DCS-1). Water vapor content was monitored by a humidity meter (Center 310, Center). The air flow rate and initial toluene concentration was $0.2 \mathrm{~L} / \mathrm{min}$ and $100 \mathrm{ppm}$, respectively. Experimental data were recorded after the reaction reached steady state. More than five data samples were collected and averaged for the calculation of toluene and $\mathrm{O}_{3}$ removal efficiency. 


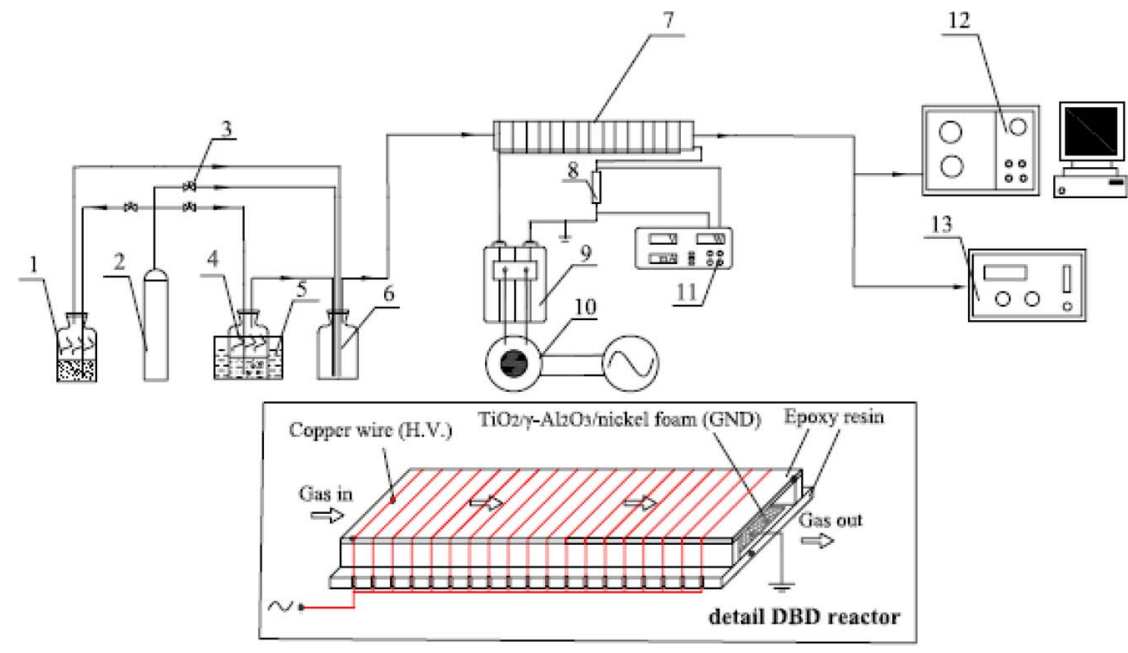

(1) bubbler for water vapor production; (2) dry air cylinder; (3) mass flow controller; (4) bubbler for toluene vapor production; (5) water bath; (6) buffer; (7) DBD reactor; (8) resistance; (9) $\mathrm{AC}$ transformer; (10) voltage regulator; (11) digital power meter; (12) GC (13) ozone analyzer.

Fig. 1. Schematics of the experimental setup.

\section{B. Catalysts Preparation}

Two catalysts (i.e., $\mathrm{MnOx} / \gamma-\mathrm{Al}_{2} \mathrm{O}_{3} /$ nickel foam and $\mathrm{TiO}_{2} / \gamma-\mathrm{Al}_{2} \mathrm{O}_{3} /$ nickel foam) were used in this paper. A commercial nickel foam support $(150 \mathrm{~mm} \times 25 \mathrm{~mm} \times 2 \mathrm{~mm})$ was impregnated in the sol of $\mathrm{Al}_{2} \mathrm{O}_{3} \cdot \mathrm{nH}_{2} \mathrm{O}$, then dried at $100{ }^{\circ} \mathrm{C}$ for $2 \mathrm{~h}$ and calcined at $550{ }^{\circ} \mathrm{C}$ for $4 \mathrm{~h}$ to get $\gamma-\mathrm{Al}_{2} \mathrm{O}_{3} /$ nickel foam hybrid support. The hybrid support was impregnated in manganese nitrate solution, then dried at $100{ }^{\circ} \mathrm{C}$ for $2 \mathrm{~h}$ and calcined at $550{ }^{\circ} \mathrm{C}$ for $4 \mathrm{~h}$ to get $\mathrm{MnOx} / \gamma-\mathrm{Al}_{2} \mathrm{O}_{3} /$ nickel foam catalyst. $\mathrm{TiO}_{2}$ was put into distilled water and dispersed fully in an ultrasonic cleaner bath to get $8 \%$ wt. $\mathrm{TiO}_{2}$ slurry. The $\gamma-\mathrm{Al}_{2} \mathrm{O}_{3} /$ nickel foam was dipped into the $\mathrm{TiO}_{2}$ slurry, impregnated for $30 \mathrm{~min}$ and then dried at $100{ }^{\circ} \mathrm{C}$ for $2 \mathrm{~h}$ to get $\mathrm{TiO}_{2} / \gamma-\mathrm{Al}_{2} \mathrm{O}_{3} /$ nickel foam catalyst. The weight of loaded $\mathrm{MnOx}$ and $\mathrm{TiO}_{2}$ is $0.45 \mathrm{~g}$.

In this paper, the TRE, carbon balance, and $\mathrm{CO}_{2}$ selectivity were defined as follows:

Toluene removal efficiency(TRE) : TRE(\%)

$$
=\frac{[\text { toluene }]_{\text {inlet }}-[\text { toluene }]_{\text {outlet }}}{[\text { toluene }]_{\text {inlet }}} \times 100 \%
$$

Carbon balance : Carbon balance( $\%)$

$$
\begin{gathered}
=\frac{[\mathrm{CO}]+\left[\mathrm{CO}_{2}\right]}{7\left([\text { toluene }]_{\text {inlet }}-[\text { toluene }]_{\text {outlet }}\right)} \times 100 \% \\
\mathrm{CO}_{2} \text { selectivity }\left(\mathrm{S}_{\mathrm{CO} 2}\right): \mathrm{S}_{\mathrm{CO}_{2}}(\%) \\
=\frac{\left[\mathrm{CO}_{2}\right]}{7\left([\text { toluene }]_{\text {inlet }}-[\text { toluene }]_{\text {outlet }}\right)} \times 100 \%
\end{gathered}
$$

where $[\text { toluene }]_{\text {inlet }}$ and [toluene $]_{\text {outlet }}$ is the toluene concentration (ppm) in the feed and effluent gas, respectively; [CO] and $\left[\mathrm{CO}_{2}\right]$ is the $\mathrm{CO}$ and $\mathrm{CO}_{2}$ concentration (ppm) in the products, respectively. Water vapor content(s) was defined as follows:

$$
s(\%)=\frac{f \times Q}{\rho_{\text {air }}}
$$

where $f, Q$, and $\rho_{\text {air }}$ is relative humidity ( $\left.\%\right)$, saturated water vapor $\left(\mathrm{g} / \mathrm{m}^{3}\right)$, and air density $\left(\mathrm{g} / \mathrm{m}^{3}\right)$ at $25^{\circ} \mathrm{C}$, respectively.

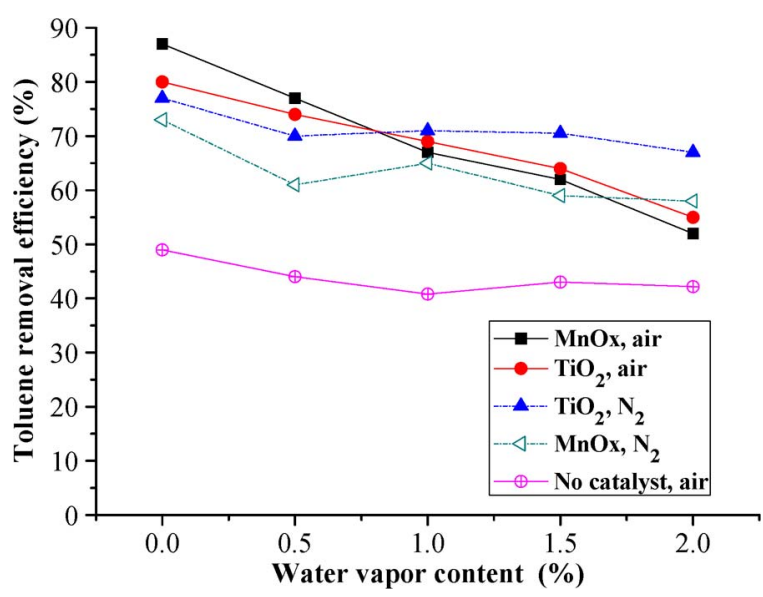

Fig. 2. Effect of water vapor content on toluene removal efficiency with/without the catalyst in air/ $\mathrm{N}_{2}$ stream.

\section{RESUlts AND Discussion}

\section{A. Effect of Water Vapor Content on TRE}

Fig. 2 shows the effect of water vapor content on the TRE under different conditions. It can be found that the TRE was decreased from 49 to $40.8 \%$ with the increase of water vapor content from 0 to $2 \%$ in the NTP. Water vapor plays a dual role in toluene destruction. Water vapor content enhances the formation of hydroxyl radicals $(\mathrm{OH} \bullet)[9]$, [13]. On the other hand, it also has an adverse effect on toluene removal due to electronegative characteristics [13], [14]. In addition, the increased water vapor content limits the electron density and quenches the active chemical species [13]. The TRE reached the highest and the lowest under the condition of 0 and $1 \%$ water vapor content, respectively. The effect of moisture in the NTP process is somewhat different from some previous literature since it depends on many factors such as the characteristics of pollutants, high-voltage power sources, reactors, and water vapor content.

The role of water vapor in the PDC process is much more complicated than that in the NTP process. Both energetic 
electrons and catalysts are involved in the PDC process. The TRE is much more sensitive to the change of water vapor content in the PDC process than that in the NTP process. As shown in Fig. 2, the TRE in air stream decreased from 87 to $52 \%$ and from 80 to $55 \%$ in the PDC process using $\mathrm{MnOx}$ and $\mathrm{TiO}_{2}$ catalyst, respectively. Water vapor greatly depressed toluene decomposition in the PDC. It can be found the TRE in nitrogen stream was decreased from 73 to $58 \%$ and from 77 to $67 \%$ with $\mathrm{MnOx}$ and $\mathrm{TiO}_{2}$ catalyst, respectively. Energetic electron and nitrogen radicals resulted from electron impact are the dominant species responsible for toluene destruction in the $\mathrm{N}_{2}$ stream. Water vapor will quench energetic electrons, leading to the decrease of TRE with the increased water vapor content, as observed in Fig. 2. Thus, it is understandable that the highest TRE in the $\mathrm{N}_{2}$ gas stream was obtained in the absence of water vapor. The TRE is more sensitive to the change of water vapor content in the air stream when compared with that in the $\mathrm{N}_{2}$ stream in the PDC process. $\mathrm{O}_{3}$ can be abundantly generated during the discharge. However, its formation was suppressed due to the extinguishing of energetic electrons by water vapor. It can be found that the $\mathrm{O}_{3}$ concentration dropped from 156 to $78 \mathrm{ppm}$ with the increase of water vapor content from 0 to $2 \%$ (Fig. 3). $\mathrm{O}_{3}$ can be efficiently decomposed by the catalyst. About 82.1 and $78.2 \% \quad \mathrm{O}_{3}$ was decomposed by the $\mathrm{MnOx}$ and $\mathrm{TiO}_{2}$ catalyst, respectively, at $0 \%$ water vapor content. With the increased water vapor content from 0 to $2 \%$, the decomposed $\mathrm{O}_{3}$ amount was decreased from 128 to $59.5 \mathrm{ppm}$ and from 122 to $34 \mathrm{ppm}$, in the PDC process using MnOx and $\mathrm{TiO}_{2}$ catalyst, respectively. The results showed that water vapor depressed $\mathrm{O}_{3}$ catalytic decomposition since it might compete with ozone for the adsorption sites of catalysts [15]. $\mathrm{O}_{3}$ is a strong oxidant and can be decomposed into $\mathrm{O}$, which is highly reactive and can efficiently oxidize toluene. Thus, water vapor can impose negative effect on toluene removal by inhibiting $\mathrm{O}_{3}$ formation of and subsequent catalytic ozonation. The rate constants of $\mathrm{O}_{3}, \mathrm{O}$, and $\bullet \mathrm{OH}$ with toluene are $1.5 \times 10^{-22}$, $2.2 \times 10^{-14}$ and $7 \times 10^{-13} \mathrm{~L} \cdot \mathrm{mol}^{-1} \cdot \mathrm{s}^{-1}$, respectively. $\mathrm{O}$ and - $\mathrm{OH}$ are much more active than $\mathrm{O}_{3}$ and should be the main active species responsible for toluene destruction in the PDC besides of energetic electrons. Both $\mathrm{O}$ and $\bullet \mathrm{OH}$ were influenced by water vapor content. Some water vapor is useful to the formation of $\bullet \mathrm{OH}$ while too much water vapor is negative due to the deactivation of catalysts.

In addition, water vapor deposited on the catalyst would cover the catalytic active sites and deactivate the catalyst [14], [17]. To prove this, the $\mathrm{TiO}_{2}$ catalyst adsorbed with water vapor before reaction was compared with that without the adsorption of water vapor, as shown in Fig. 4. It can be found that the TRE reached $84.4 \%$ in the latter while it was only $64.4 \%$ in the former; and the corresponding $\mathrm{O}_{3}$ removal efficiency is $93 \%$ and $63 \%$, respectively. This is because that water vapor deposited on the catalyst prevents the adsorption of toluene and $\mathrm{O}_{3}[16]$, leading to depress destruction of both toluene and $\mathrm{O}_{3}$. In summary, water vapor imposed negative effects on toluene removal in three ways: 1) quenching of high-energy electrons; 2) inhibition of ozone formation and decomposition; and 3) suppression of catalytic ozonation.
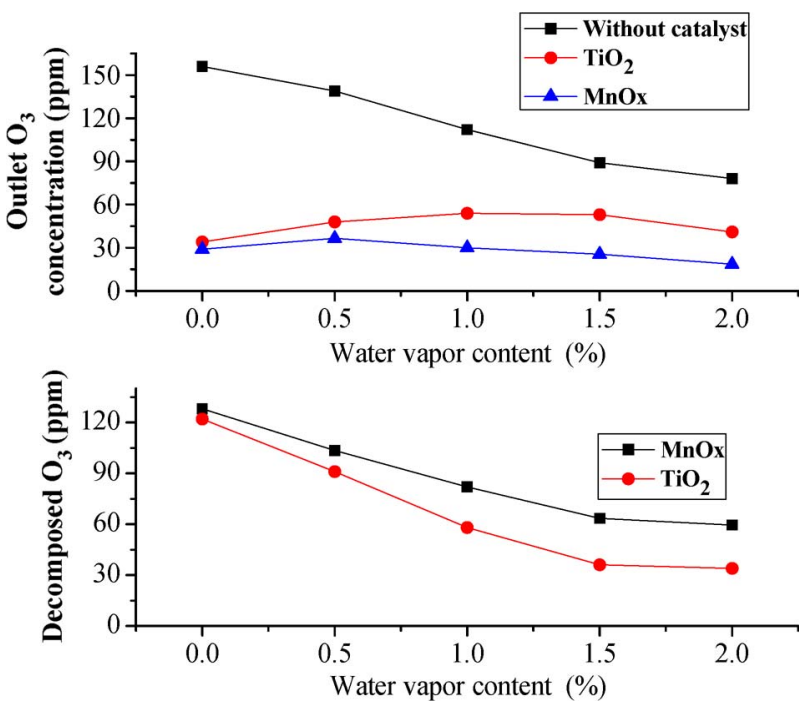

Fig. 3. Effect of water vapor content on outlet $\mathrm{O}_{3}$ concentration and decomposed $\mathrm{O}_{3}$.

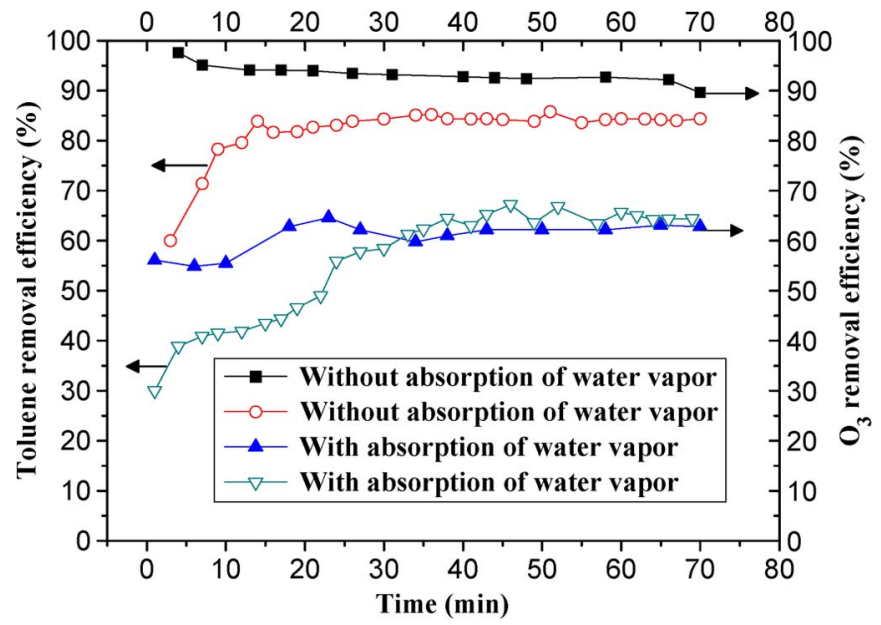

Fig. 4. Comparison of removal efficiency of $\mathrm{O}_{3}$ and toluene with/without preadsorption of water vapor.

\section{B. Effect of Water Vapor Content on Carbon Balance and $\mathrm{CO}_{2}$ Selectivity}

Water vapor has a significant effect on carbon balance and $\mathrm{CO}_{2}$ selectivity in the PDC, as shown in Fig. 5. With increased water vapor content from 0 to $2 \%$, carbon balance and $\mathrm{CO}_{2}$ selectivity both initially increased and then dropped. However, too much water vapor would reduce the $\mathrm{O}_{3}$ concentration, limit the electron density, and quench the active chemical species [13]. There should be an optimum water vapor content for the best carbon balance. For the $\mathrm{TiO}_{2}$ catalyst, carbon balance and $\mathrm{CO}_{2}$ selectivity varied from 82 to $56 \%$ and from 70 to $46 \%$, respectively, in the range of $0 \% \sim 2 \%$ water vapor content. Both carbon balance and $\mathrm{CO}_{2}$ selectivity reached the maximum of 82 and $70 \%$, respectively, at $1 \%$ water vapor content. For the $\mathrm{MnOx}$ catalyst, carbon balance and $\mathrm{CO}_{2}$ selectivity varied from 77 to $48 \%$ and from 67 to $37 \%$, respectively. Both carbon balance and $\mathrm{CO}_{2}$ selectivity reached the maximum of 77 and $67 \%$, respectively, at $1.5 \%$ water vapor content. As described previously, a small amount of water vapor is essential to the 


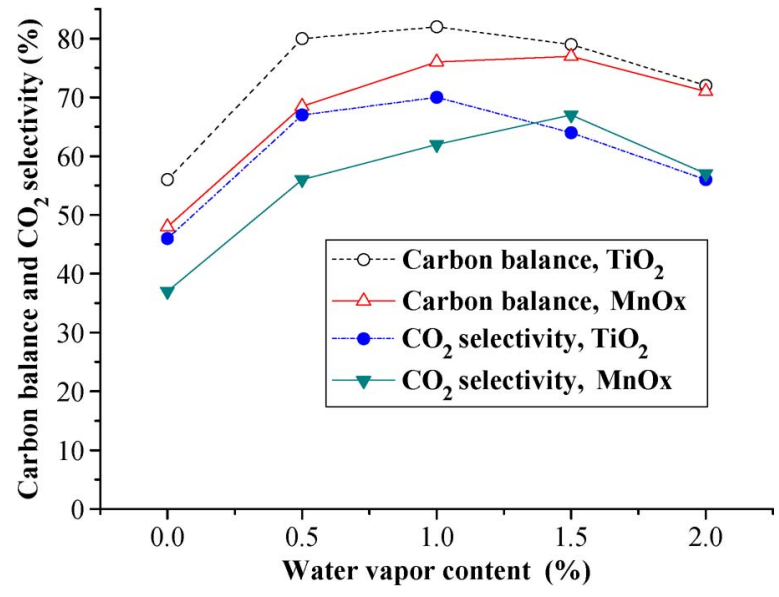

Fig. 5. Effect of water vapor content on carbon balance and $\mathrm{CO}_{2}$ selectivity in the PDC.

formation of $\mathrm{OH} \bullet$, which is highly reactive for toluene oxidation. $\mathrm{TiO}_{2}$ exhibited higher carbon balance and $\mathrm{CO}_{2}$ selectivity probably because $\mathrm{OH} \bullet$ can be formed more easily on $\mathrm{TiO}_{2}$ than on $\mathrm{MnOx}$ catalyst. Comparing Fig. 2 with Fig. 5, the effect of water vapor content on TRE, carbon balance, and $\mathrm{CO}_{2}$ selectivity is greatly different in the NTP and PDC process. Although the TRE in the PDC process with $\mathrm{TiO}_{2}$ catalyst is close to that with $\mathrm{MnOx}$ catalyst, the carbon balance and $\mathrm{CO}_{2}$ selectivity differed at different water vapor content. Thus, there is no causal relationship between TRE and carbon balance and $\mathrm{CO}_{2}$ selectivity. Carbon balance and $\mathrm{CO}_{2}$ selectivity mainly depends on the concentration of oxidant radicals (such as $\mathrm{OH} \bullet$ and $\mathrm{O}$ ), which is affected by the water vapor content and the characteristic of catalysts. The improvement of carbon balance and $\mathrm{CO}_{2}$ selectivity needs further investigation.

\section{CONCLUSION}

Water vapor is a critical operating parameter during the control of ambient pollution using the PDC technology. It affected both the catalytic performance and discharge. Water vapor exhibited negative effect on toluene removal since it suppressed the formation and catalytic decomposition of $\mathrm{O}_{3}$. It would deposit on the surface of the catalyst and covered the catalytic active sites, hence deactivating the catalyst. The highest carbon balance and $\mathrm{CO}_{2}$ selectivity were obtained with water vapor content between 0.5 and $1.5 \%$.

\section{REFERENCES}

[1] A. M. Harling, V. Demidyuk, S. J. Fischer, and J. C. Whitehead, "Plasmacatalysis destruction of aromatics for environmental clean-up: Effect of temperature and configuration," Appl. Catal. B, Environ., vol. 82, no. 3/4, pp. 180-189, Aug. 2008.

[2] H. L. Chen, H. M. Lee, S. H. Chen, M. B. Chang, S. J. Yu, and S. N. Li, "Removal of volatile organic compounds by single-stage and two-stage plasma catalysis systems: a review of the performance enhancement mechanisms, current status, and suitable applications," Environ. Sci. Technol., vol. 43, no. 7, pp. 2216-2227, Feb. 2009.

[3] H. H. Kim, S. M. Oh, A. Ogata, and S. Futamura, "Decomposition of gasphase benzene using plasma-driven catalyst (PDC) reactor packed with $\mathrm{Ag} / \mathrm{TiO}_{2}$ catalyst," Appl. Catal. B, Environ, vol. 56, no. 3, pp. 213-220, Mar. 2005.

[4] U. Roland, F. Holzer, and E. D. Kopinke, "Combination of non-thermal plasma and heterogeneous catalysis for oxidation of volatile organic com-

pounds: Part 2. Ozone decomposition and deactivation of $\gamma-\mathrm{Al}_{2} \mathrm{O}_{3}$," Appl. Catal. B, Environ., vol. 58, no. 3/4, pp. 217-226, Jun. 2005.

[5] J. Van Durme, J. Dewulf, C. Leys, and H. Van Langenhove, "Combining non-thermal plasma with heterogeneous catalysis in waste gas treatment: A review," Appl. Catal. B, Environ., vol. 78, no. 3/4, pp. 324-333, Feb. 2008

[6] H.-H. Kim, A. Ogata, and S. Futamura, "Oxygen partial pressuredependent behavior of various catalysts for the total oxidation of VOCs using cycled system of adsorption and oxygen plasma," Appl. Catal. B, Environ., vol. 79, no. 4, pp. 356-367, Mar. 2008.

[7] M. Schiorlin, E. Marotta, M. Rea, and C. Paradisi, "Comparison of toluene removal in air at atmospheric conditions by different corona discharges," Environ. Sci. Technol., vol. 43, no. 24, pp. 9386-9392, Nov. 2009.

[8] A. Ogata, N. Shintani, K. Yamanouchi, K. Mizuno, S. Kushiyama, and T. Yamamoto, "Effect of water vapor on benzene decomposition using a nonthermal-discharge plasma reactor," Plasma Chem. Plasma Process., vol. 20, no. 4, pp. 453-467, Dec. 2000.

[9] Z. Bo, J. H. Yan, X. D. Li, Y. Chi, K. F. Cen, and B. G. Cheron, "Effects of oxygen and water vapor on volatile organic compounds decomposition using gliding arc gas discharge," Plasma Chem. Plasma Process., vol. 27, no. 5, pp. 546-558, 2007.

[10] Y.-P. I, Y.-C. Liu, K.-Y. Han, and T.-C. She, "Construction of a lowpressure microwave plasma reactor and its application in the treatment of volatile organic compounds," Environ. Sci. Technol., vol. 38, no. 13, pp. 3785-3791, May 2004.

[11] S. Futamura, A. H. Zhang, G. Prieto, and T. Yamamoto, "Factors and intermediates governing byproduct distribution for decomposition of butane in nonthermal plasma," IEEE Trans. Ind. Appl., vol. 34, no. 5, pp. 967974, Sep./Oct. 1998.

[12] C. Ayrault, J. Barrault, N. Blin-Simiand, F. Jorand, S. Pasquiers A. Rousseau, and J. M. Tatibouët, "Oxidation of 2-heptanone in air by a DBD-type plasma generated within a honeycomb monolith supported Pt-based catalyst," Catal. Today, vol. 89, no. 1/2, pp. 75-81, Feb. 2004.

[13] Y. F. Guo, D. Q. Ye, K. F. Chen, and Y. F. Tian, "Humidity effect on toluene decomposition in a wire-plate dielectric barrier discharge reactor," Plasma Chem. Plasma Process., vol. 26, no. 3, pp. 237-249, Jun. 2006.

[14] T. Zhu, J. Li, Y. Jin, Y. Liang, and G. Ma, "Decomposition of benzene by non-thermal plasma processing: Photocatalyst and ozone effect," Int. J. Environ. Sci. Technol., vol. 5, no. 3, pp. 375-384, 2008.

[15] J. Van Durme, J. Dewulf, K. Demeestere, C. Leys, and H. Van Langenhove, "Post-plasma catalytic technology for the removal of toluene from indoor air: Effect of humidity," Appl. Catal. B, Environ., vol. 87, no. 1/2, pp. 78-83, Mar. 2009.

[16] P. Y. Zhang, F. Y. Liang, G. Yu, Q. Chen, and W. P. Zhu, "A comparative study on decomposition of gaseous toluene by $\mathrm{O}_{3} / \mathrm{UV}, \mathrm{TiO}_{2} / \mathrm{UV}$ and $\mathrm{O}_{3} / \mathrm{TiO}_{2}$ /UV," J. Photochem. Photobiol. A, Chem., vol. 156, no. 1-3, pp. 189-194, Mar. 2003.

[17] C. H. Cho and S. K. Ihm, "Development of new vanadium-based oxide catalysts for decomposition of chlorinated aromatic pollutants," Environ. Sci. Technol., vol. 36, no. 7, pp. 1600-1606, Mar. 2002.

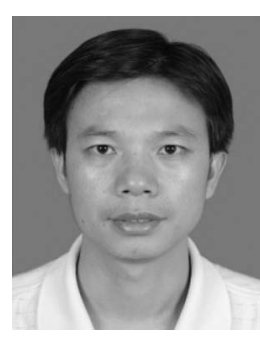

lysis materials
Haibao Huang received the Ph.D. degree in environmental engineering from South China University of Technology, Guangzhou, China, in 2008.

From 2008 to 2009, he was a Postdoctoral Fellow with Tsinghua University, Beijing, China. Since 2009, he has been with the University of Hong Kong, Pok Fu Lam, Hong Kong, as a Postdoctoral Fellow. He has published more than 15 scientific articles. His main research interests include nonthermal plasma technology, photocatalysis, room-temperature destruction of air pollutants, and environmental cata- 


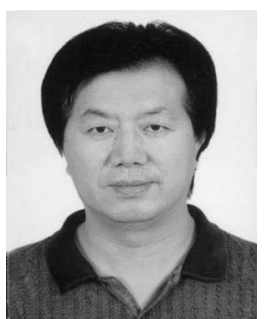

Daiqi Ye received the Ph.D. degree in industrial catalysis from South China University of Technology (SCUT), Guangzhou, China, in 1990.

He is currently the Director of Environmental Engineering Department and Chief Professor of Air Pollution Control Engineering, SCUT. He is the first Author or corresponding Author of more than 150 scientific papers, and 17 China patents/patent applications. His main research interests include hazardous airborne pollutants elimination with nonthermal plasma technology, volatile organic compounds control, catalytic elimination of vehicle exhaust emission, and nitrogen oxides removal with SCR/SNCR technology.

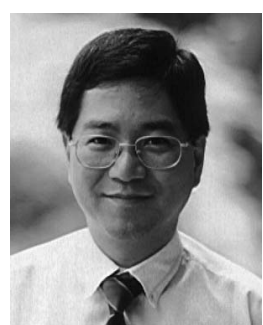

Dennis Y. C. Leung received the B.Sc. (Eng.) and Ph.D. degrees from the department of mechanical engineering at the University of Hong Kong (HKU), Pok Fu Lam, Hong Kong.

He joined HKU in 1993 as a Lecturer in Environmental Engineering and is currently a Professor of the Department of Mechanical Engineering, specializing in air pollution and renewable energy. He has published more than 250 articles, including 130 peerreviewed journal papers in the field of air pollution control, dispersion modeling, and energy conversion. Dr. Leung received the Outstanding Earth Champion Hong Kong award in 2008 in recognizing his contributions in protecting the environment. 